\title{
Activation of PGK1 under hypoxic conditions promotes glycolysis and increases stem cell-like properties and the epithelial-mesenchymal transition in oral squamous cell carcinoma cells via the AKT signalling pathway
}

\author{
YADONG ZHANG ${ }^{1,2}$, HONGSHI CAI ${ }^{1,2}$, YAN LIAO ${ }^{1,2}$, YUE ZHU $^{1,2}$, FANG WANG $^{1,2}$ and JINSONG HOU ${ }^{1,2}$ \\ ${ }^{1}$ Department of Oral and Maxillofacial Surgery, Hospital of Stomatology, Guanghua School of Stomatology; \\ ${ }^{2}$ Guangdong Provincial Key Laboratory of Stomatology, Sun Yat-sen University, Guangzhou, Guangdong 510055, P.R. China
}

Received January 13, 2020; Accepted April 22, 2020

DOI: 10.3892/ijo.2020.5083

\begin{abstract}
Although it has been previously documented that a hypoxic environment can promote glycolysis and the malignant progression of oral squamous cell carcinoma (OSCC) cells, the specific underlying mechanism remains unclear. Phosphoglycerate kinase 1 (PGK1) has been previously reported to serve an important role in tumor metabolism. The aim of the present study was to investigate the effects of hypoxia and PGK1 on glycolysis, stem cell-like properties and epithelial-mesenchymal transition (EMT) in OSCC cells. Cell Counting Kit-8 assays were performed to examine tumor cell viability under hypoxic conditions. Sphere formation, immunohistochemistry, western blotting, Transwell assays and mouse xenograft studies were performed to assess the biological effects of PGK1. Under hypoxic conditions, phosphoglycerate PGK1 expression was found to be upregulated, which resulted in the potentiation of stem cell-like properties and enhancement of EMT. However, PGK1 knockdown reversed hypoxia-mediated glycolysis, stem cell-like properties, EMT in addition to inhibiting OSCC cell invasion and migration. PGK1 knockdown also inhibited tumour growth, whilst the overexpression of PGK1 was demonstrated to promote tumour growth in mouse xenograft models in vivo. Downstream, activation of the AKT signalling pathway reversed the series of changes induced by PGK1 knockdown. PGK1 expression was found to be upregulated in human OSCC tissues, which was associated with the pathological differentiation of tumours and lymph node metastasis. To conclude, results from the present
\end{abstract}

Correspondence to: Professor Jinsong Hou, Department of Oral and Maxillofacial Surgery, Hospital of Stomatology, Guanghua School of Stomatology, Sun Yat-sen University, Guangzhou, Guangdong 510055, P.R. China

E-mail: houjs@mail.sysu.edu.cn

Key words: hypoxia, phosphoglycerate kinase 1, epithelialmesenchymal transition, stem cell-like properties, oral squamous cell carcinoma study demonstrate that hypoxia can increase PGK1 expression, resulting in the promotion of glycolysis, enhancing stem cell-like properties and EMT by activating AKT signalling in OSCC.

\section{Introduction}

Oral squamous cell carcinoma (OSCC) is the most prevalent malignant tumour in the oral and maxillofacial region (1). The high incidence of oral cancer is attributed to physical, chemical and biological factors. According to the statistics of American Cancer Association, there were about 48,000 newly diagnosed cases of OSCC in 2016, which accounted for 3\% of all new malignant tumor cases (2-5). At present, surgery combined with radiotherapy and chemotherapy is the primary treatment option for oral cancer. However, the 5-year survival rate of patients with oral cancer has not significantly improved over the past decade $(6,7)$. The invasive and metastatic ability of tumour cells is one of the main factors affecting the prognosis of patients (8). The growth of tumours is influenced by the surrounding microenvironment (9). However, the molecular mechanism underlying the rapid tumour growth, maintenance of invasiveness and metastatic capability remain unclear.

Epithelial-mesenchymal transformation (EMT) refers to the biological process in which epithelial cells transform into cells that exhibit a more mesenchymal phenotype. It has been previously reported to serve an important role in embryonic development, wound healing and tumour metastasis (10-14). The main characteristic of EMT is a reduction in the expression of cell adhesion molecules such as E-cadherin and the conversion of expression profiles from keratin to vimentin in the cytoskeleton (10). It is an important biological process for the invasion and migration of OSCC cells. The regulation of EMT involves a complex network of signalling pathways, including those of the transforming growth factor- $\beta$ family, Wnt, Notch, epidermal growth factor (EGF), hepatocyte growth factor, fibroblast growth factor (FGF) and hypoxia-inducible factor (HIF) (15-17). Malignant tumour cells mainly meet their metabolic demands through glycolysis, even under a plentiful supply of oxygen, in a phenomenon known as the Warburg effect (18). Glycolysis has 
been previously demonstrated to promote the invasion of HeLa cells (19). A number of transcription factors, including HIF-1 $\alpha$, $\mathrm{c}-\mathrm{Myc}, \mathrm{NF}-\kappa \mathrm{B}$ and $\mathrm{p} 53$, have been previously found to be involved in the regulation of glycolysis in cancer cells (20-23). In OSCC, pyruvate kinase M1/2 dephosphorylation has been previously demonstrated to promote the Warburg effect and tumorigenesis, whilst silencing phosphofructokinase, platelet (PFKP) expression inhibited starvation-induced autophagy, glycolysis and EMT (24).

PGK participates in the second stage of glycolysis, where it catalyzes the conversion of 1,3-diphosphoglyceride into 3-phosphoglycerate, consuming a molecule of ADP and produces a molecule of ATP (25). Phosphoglycerate kinase (PGK) is an essential enzyme that is associated with the survival of every organism, where mutations in PGK results in a number of metabolic disorders, including mental retardation, neurological disorders and rhabdomyolysis (25). There are PGK two main subtypes of PGK, namely PGK1 and PGK2, both of which have similar functions and structures (26). PGK1 serves a speed limiting role in the second stage of glycolysis during the regulation of energy production and redox balance (27). Aberrant PGK1 expression has been previously associated with the occurrence of a number of diseases, including Parkinson's disease and hereditary non-spherical hemolytic anemia (28-30). By contrast, the PGK2 gene is only expressed in spermatogenic cells, where its only known function is to compensate for the inhibition of PGK1 expression caused by the inactivation of $\mathrm{X}$ chromosomes in spermatocytes (31). Since PGK1 is a mediator of glycolysis that supplies ATP for tumor cell metabolism under hypoxic conditions, it has been reported to participate in the development and progression of numerous cancer types, including renal, gastric and lung cancer (32-34).

In the present study, hypoxia-induced glycolysis was established in OSCC tumour cell lines in vitro, where the effects of PGK1 on the invasive and migratory capabilities of OSCC cells and the underlying molecular mechanism were investigated. Results from the present study demonstrated that hypoxia resulted in the activation of PGK1, in turn promoting glycolysis, increasing stem cell-like properties and promoting EMT via AKT signalling in OSCC.

\section{Materials and methods}

Patients and tissue samples. In total, 92 OSCC tissue samples and 20 matched non-cancerous tissue samples were collected from the inpatients (age range, 34-87 years; sex 58 males and 34 females) at the Affiliated Stomatological Hospital of Sun Yat-sen University (Guangzhou, China) from June 2008 to June 2017. Immunohistochemical assays for PGK1 were performed on all 112 samples. The removal of tissue samples from patients was approved by the ethical review committee of the Affiliated Stomatological Hospital of Sun Yat-sen University.

All patients received radical surgery and none received any form of pre-surgical adjuvant therapy. The clinical and pathological characteristics (sex, age, differentiation, T stage, clinical stage and lymph node metastasis) of the cancer in each patient were established in accordance with the criteria of the American Joint Committee on Cancer (35). The experiments were performed with the understanding and written consent of each subject. The study methodologies conformed to the standards set by the Declaration of Helsinki.

Antibodies. Anti-PGK1 (cat. no. ab38007), anti-SRY-box transcriptionfactor 2(Sox2; cat.no.ab93689), anti-octamer-binding transcription factor 4 (Oct4; cat. no. ab181557), anti-Nanog (cat. no. ab106465), anti-phosphorylated (p)-AKT (cat. no. ab38449) and anti-AKT (cat. no. ab8805) were purchased from Abcam (Abcam). Anti-HIF-1a (cat. no. 36169), anti-E-cadherin (cat. no. 3195), anti-vimentin (cat. no. 5741), anti-Slug (cat. no. 9585) and anti- $\beta$-actin (cat. no. 8457) primary antibodies were purchased from Cell Signalling Technology, Inc.

Cell lines and treatment. The cell lines HSC3 and HN6 were obtained from the American Type Culture Collection. Cells were cultured in DMEM medium (Gibco; Thermo Fisher Scientific, Inc.) supplemented with $10 \%$ FBS (Hyclone; GE Healthcare Life Sciences) in $5 \% \mathrm{CO}_{2}$ at $37^{\circ} \mathrm{C}$ under normoxic conditions, where the medium was replaced every day. For hypoxia treatment, cells were incubated in $1 \% \mathrm{O}_{2}, 5 \% \mathrm{CO}_{2}$ at $37^{\circ} \mathrm{C}$ for $12 \mathrm{~h}$ or $24 \mathrm{~h}$ followed by returning to normoxic conditions for subsequent experimentation. The AKT activator SC79 (cat. no. HY-18749; MedChemExpress) was dissolved in DMSO to a stock concentration of $10 \mathrm{mM}$, where a final concentration of $10 \mu \mathrm{M}$ was used at $37^{\circ} \mathrm{C}$ for $24 \mathrm{~h}$ under normoxic conditions.

RNA interference and lentiviral transfection. PGK1 and control siRNA were used in this study, which were synthesised by Guangzhou RiboBio Co., Ltd. After diluting Lipofectamine ${ }^{\circledR}$ RNAiMAX (Invitrogen; Thermo Fisher Scientific, Inc.) and PGK1 or control siRNA with Opti-MEM (Invitrogen; Thermo Fisher Scientific, Inc.), they were mixed and incubated at room temperature for $5 \mathrm{~min}$. PGK1 siRNA $(50 \mathrm{nM})$ was then introduced into HSC3 and HN6 cells for $12 \mathrm{~h}$ before treatment according to the manufacturer's protocols. Sequences of the three PGK1 siRNAs were as follows: PGK1 si-1, 5'-CCAAGT CGGTAGTCCTTAT-3'; PGK1 si-2 5'-GCTTTCCGAGCT TCACTTT-3'; PGK1 si-3 5'-TGTCACTGCTGACAAGTTT-3'. The negative control duplex used (cat. no. siN0000001-1-5), which was also provided by Guangzhou RiboBio Co., Ltd., was not homologous to any mammalian genes.

Lentiviral plasmid pLVX-mCMV-ZsGREEN-Puro was constructed to overexpress PGK1 whereas the lentiviral plasmid pLVX-shRNA-tdTomato-Puro was constructed to knock down PGK1 expression in HSC3 cells. The multiplicity of infection of both PGK1 knockdown and overexpression was 10. The sequence ligated into the lentiviral plasmid to knock down PGK1 was as follows: 5'-CTGACAAGTTTGATGA GAATGCTCGAGCATTCTCATCAAACTTGTCAGTTTT TT-3'. The lentivirus packaging process was completed by Guangzhou MingKong Co., Ltd. The recombinant virus plasmid encoding lentivirus particles and its three auxiliary packaging vector plasmids (pGag/Pol, pRev, pVSV-G) were prepared and transfected into $293 \mathrm{~T}$ cells with Lipofectamine ${ }^{\circledR} 2000$ (Invitrogen; Thermo Fisher Scientific, Inc.). The concentration of all of the plasmids used per transfection reaction into $293 \mathrm{~T}$ cells was $300 \mathrm{ng} / \mu \mathrm{l}$. 
Cell viability assay. HSC3 and HN6 cells from the control and hypoxia groups were seeded at 1,000 per well in 96-well plates and cultured for $0,24,48$ and $72 \mathrm{~h}$ at $37^{\circ} \mathrm{C}$. Cell viability was measured using a Cell Counting Kit-8 kit assay (CCK-8; Dojindo Molecular Technologies, Inc.). After adding $10 \mu \mathrm{l}$ CCK- 8 reagent per well, plates were incubated at $37^{\circ} \mathrm{C}$ for $1 \mathrm{~h}$. Absorbance in each well was measured at $450 \mathrm{~nm}$ using a microplate reader (Bio-Rad Laboratories, Inc.) according to the manufacturer protocols.

Immunohistochemistry. The tissues obtained were first fixed in $4 \%$ paraformaldehyde for $24 \mathrm{~h}$ at room temperature and embedded in paraffin to immobilise the tissues, following which immunohistochemical staining of $3-\mu \mathrm{m}$ thick paraffin sections was subsequently performed. The tissue sections were first deparaffinized with xylene and rehydrated with a descending ethanol gradient before being boiled in a pressure cooker with sodium citrate buffer at $99^{\circ} \mathrm{C}$ for $20 \mathrm{~min}$ for antigen retrieval. Endogenous peroxidase/phosphatase activities within the sections were then quenched at room temperature for 10 min using $3 \%$ hydrogen peroxide, followed by blocking in 5\% goat serum (Wuhan Boster Biological Technology, Ltd.) at room temperature for $30 \mathrm{~min}$. The sections were then incubated with the respective PGK1, E-cadherin, Vimentin, Slug, Sox 2, Oct4 and Nanog primary antibodies (1:250 dilution) overnight at $4^{\circ} \mathrm{C}$, following which they were incubated with horseradish-peroxidase (HRP)-conjugated secondary antibodies (1:200; cat. no. 7074s; Cell Signaling Technology, Inc.) diluted in 1\% BSA (Wuhan Boster Biological Technology, Ltd.) at room temperature for $30 \mathrm{~min}$. For color development, 3,3'-diaminobenzidine was used. An Axio Imager Z2 light microscope (magnifications, x100 and x400; Zeiss AG) was used for image acquisition. Immunohistochemical staining was assessed in terms of staining intensity and the proportion of positively staining cells using Image-Pro Plus 6.0 software (Media Cybernetics, Inc.). The scoring system for staining intensity was as follows: i) 0 , no staining; ii) 1 , weak staining; iii) 2, medium staining; and iv) 3, strong staining. The scoring system for the proportion of positive cells was determined as follows: i) $0,0 \%$; ii) $1,25 \%$; iii) $2,50 \%$; iv) 3 , $75 \%$; and v) 4, 100\%. These two scores were then multiplied together to give the final score, where a score $>4$ was classified as high expression whereas a score $\leq 4$ was classified as low expression.

Western blot analysis. Cells were collected and treated at $4{ }^{\circ} \mathrm{C}$ for 30 min with RIPA lysis buffers (Thermo Fisher Scientific, Inc.) supplemented with protease inhibitors and phosphatase inhibitors (Thermo Fisher Scientific, Inc.). Cell lysates were collected and centrifuged at $4^{\circ} \mathrm{C}$ for $30 \mathrm{~min}$ at $14,000 \mathrm{x} \mathrm{g}$. The supernatant was collected and protein concentration was determined using a bicinchoninic acid protein assay kit (CoWin Biosciences). Total protein $(25 \mu \mathrm{g})$ was subsequently separated by $10 \%$ SDS-PAGE and transferred onto a polyvinylidene fluoride membrane (EMD Millipore) with 10\% SDS-PAGE. After blocking with $10 \%$ BSA (CoWin Biosciences) at room temperature for $1 \mathrm{~h}$, the membranes were incubated with HIF-1 $\alpha$, PGK1, E-cadherin, Vimentin, Slug, Sox2, Oct4, Nanog, p-AKT, AKT or $\beta$-actin primary antibodies (1:1,000 dilution) overnight at $4^{\circ} \mathrm{C}$, followed by incubation with a HRP-conjugated secondary antibody (1:2,000 dilution; cat. no. 7074s; Cell Signaling Technology, Inc.) at room temperature for $1 \mathrm{~h}$. An enhanced chemiluminescence kit (Cell Signaling Technology, Inc.) and and the ImageQuant Las4000mini system (GE Healthcare Life Sciences) were used to visualize the bands. $\beta$-actin was used as an internal control. The signal intensities were quantified using ImageJ version $1.48 \mathrm{u}$ software (National Institutes of Health)

Glucose consumption and lactate production analysis. Cells were seeded into 6-well plates at the same density of $2.5 \times 10^{5}$ cells per well and cultured under hypoxic conditions for $12 \mathrm{~h}$ followed by incubation under normoxic conditions for $12 \mathrm{~h}$ after siRNA transfection. The cell culture supernatants were obtained from each treatment group, where glucose consumption and lactic acid production were measured. Glucose consumption was measured at $37^{\circ} \mathrm{C}$ for 15 min using glucose detection kits (cat. no. F006-1-1; Nanjing Jiancheng Bioengineering Institute) and lactic acid production was measured at $37^{\circ} \mathrm{C}$ for 5 min using lactic acid detection kits (cat. no. A019-2-1; Nanjing Jiancheng Bioengineering Institute) in accordance with the manufacturer's protocol.

Sphere formation. The sphere formation assays were performed in ultra-low attachment 24-well plates (Corning, Inc.). A total of 1,000 cells were seeded into each well, where DMEM containing 2\% B27 (Invitrogen; Thermo Fisher Scientific, Inc.), $20 \mathrm{ng} / \mathrm{ml}$ basic fibroblast grow th factor (bFGF; Invitrogen; Thermo Fisher Scientific, Inc.) and $20 \mathrm{ng} / \mathrm{ml}$ epidermal growth factor (EGF; Invitrogen; Thermo Fisher Scientific, Inc.) were added. The experimental group received hypoxia treatment $\left(1 \% \mathrm{O}_{2}, 5 \% \mathrm{CO}_{2}\right)$ at $37^{\circ} \mathrm{C}$ for $12 \mathrm{~h}$, whilst control cells were incubated in normoxic $\left(95 \%\right.$ air $\left./ 5 \% \mathrm{CO}_{2}\right)$ conditions without hypoxia treatment. Both treatment groups were then incubated under normoxic $\left(95 \%\right.$ air $\left./ 5 \% \quad \mathrm{CO}_{2}\right)$ conditions at $37^{\circ} \mathrm{C}$ for 14 days. The resulting parameters of sphere formation, including the diameter of spheres and the number of spheres per 1,000 cells, were observed using an Axio Imager Z2 light microscope (magnification, x100; Carl Zeiss AG).

Migration and invasion assay. For cell migration, $4 \times 10^{4}$ cells were seeded into the upper chamber of Transwell assay plates (24-well insert; pore size, $8 \mu \mathrm{m}$; BD Biosciences) suspended in serum-free medium $12 \mathrm{~h}$ following normoxic or hypoxic treatment. The lower chamber was filled with DMEM supplemented with $10 \%$ FBS. For cell invasion, Matrigel (Corning, Inc.) was added into the upper chambers at $37^{\circ} \mathrm{C}$ for $1 \mathrm{~h}$ in accordance with the manufacturer's protocols, following which $8 \times 10^{4}$ cells were seeded into the upper chambers with Matrigel-coated membranes $12 \mathrm{~h}$ following normoxic or hypoxic treatment. The Transwell chambers were then incubated at $37^{\circ} \mathrm{C}$ under normoxic conditions ( $5 \% \mathrm{CO}_{2}$ atmosphere) for $36 \mathrm{~h}$. After incubation, Transwell membranes was fixed with $4 \%$ paraformaldehyde at room temperature for $30 \mathrm{~min}$, stained with $0.1 \%$ crystal violet at room temperature for $20 \mathrm{~min}$ and observed under the Axio Imager Z2 light microscope (magnification, x100; Carl Zeiss AG). The number of migrated and invaded cells was then counted in five randomly selected fields per chamber. 

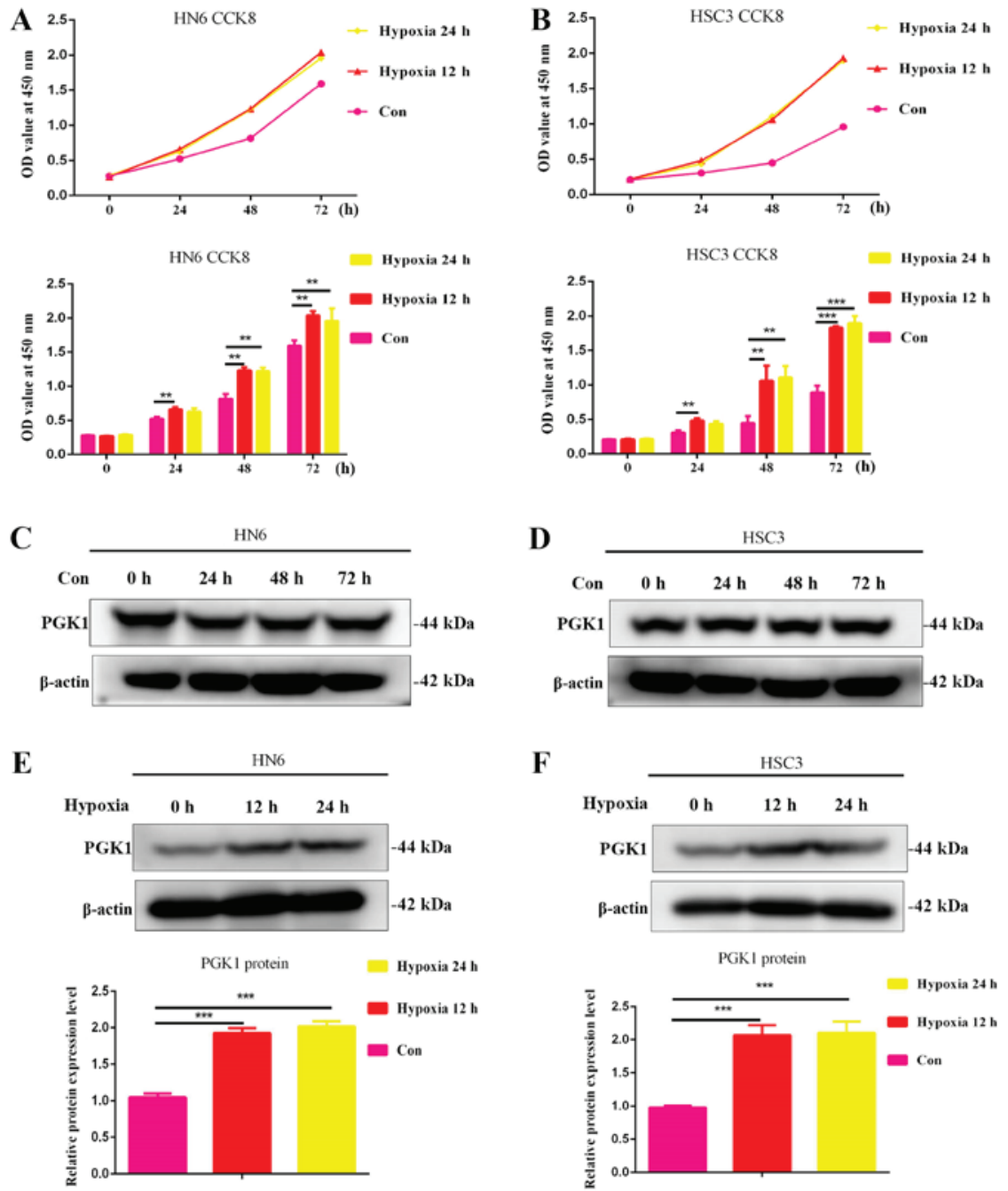

Figure 1. Hypoxia increases oral cancer cell viability and promotes the expression of PGK1. (A) HN6 and (B) HSC3 cells were cultured under hypoxic conditions for $0,6,12,18$ and $24 \mathrm{~h}$, following which cell viability was measured using CCK-8 assays. Western blotting was used to measure changes in PGK1 expression in (C) HN6 and (D) HSC3 cells after normal culture conditions for 0, 24, 48 and $72 \mathrm{~h}$. Western blotting was used to measure changes in PGK1 expression in (E) HN6 and (F) HSC3 cells following 12 and $24 \mathrm{~h}$ culturing under hypoxic conditions. ${ }^{* *} \mathrm{P}<0.01$ and ${ }^{* * *} \mathrm{P}<0.001$, $\mathrm{n}=3$. Con, control. PGK1, phosphoglycerate kinase 1; OD, optical density; CCK8, Cell Counting Kit-8.

Tumorigenesis in nude mice. A total of 20 female SCID mice (age, 4-6 weeks; weight, 20-25 g) were purchased from the Laboratory Animal Center of Sun Yat-sen University (Guangzhou, China) and maintained under pathogen-free conditions. The temperature of feeding environment is controlled at $18-26^{\circ} \mathrm{C}$ under normoxic conditions, the relative humidity is $40-70 \%$ and 12 -h light/dark cycle. All mice had free access to food and water. SCID mice were randomly divided into the following four groups ( $\mathrm{n}=5$ in each group): i) Overexpression control (Vector); ii) overexpression (PGK1); iii) knockdown control group (shVector); and iv) knockdown (shPGK1). HSC3 cells were digested by trypsin for $3 \mathrm{~min}$, neutralized with $10 \%$ FBS medium and collected by centrifugation. Then, HSC 3 cells $\left(1 \times 10^{6}\right)$ were diluted in $200 \mu$ sterile PBS and injected into the unilateral abdominal region adjacent to the axilla of the hind limbs using a $1 \mathrm{ml}$ syringe. Tumour volume was measured weekly (tumour volume $=$ length $\mathrm{x}$ wi dth $\mathrm{x}$ width) / 2) and all mice were euthanised after 1 month after cell injection and the final tumor measurement, following which the tumour mass was measured. Tissue specimens were fixed with $4 \%$ paraformaldehyde at room temperature for $24 \mathrm{~h}$ and embedded for subsequent immunohistochemical staining. This present animal study was approved by the Experimental Animal Ethics Committee of Sun Yat-sen University (Guangzhou, China). The animal experiment lasted for 2 months. Any mice that were found to be slow growing, not eating or infected by skin ulceration caused by mutual fights were euthanized by cervical dislocation. After the tumor cells are implanted into the mice, if any of the mice were observed to suffer from anorexia, inability to eat normally, significant weight loss and other abnormalities, the nutrition (melon seeds, wheat) will be enhanced immediately. Euthanasia would be performed in case of rapid weight loss of $>20 \%$, weakness, loss of appetite, inability to drink or eat, skin ulceration and infection caused by fighting with each other. Animal health and behaviour were monitored every day and no animal was found dead during the present study. A combination of criteria was used for confirming death, including the lack of pulse or breathing and rigor mortis.

TCGA Data Collection and Processing. The gene expression RNAseq and clinical data of 566 cases of the head and neck 
A

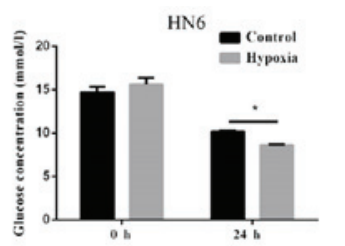

C

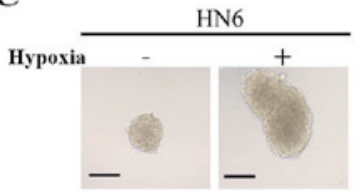

D

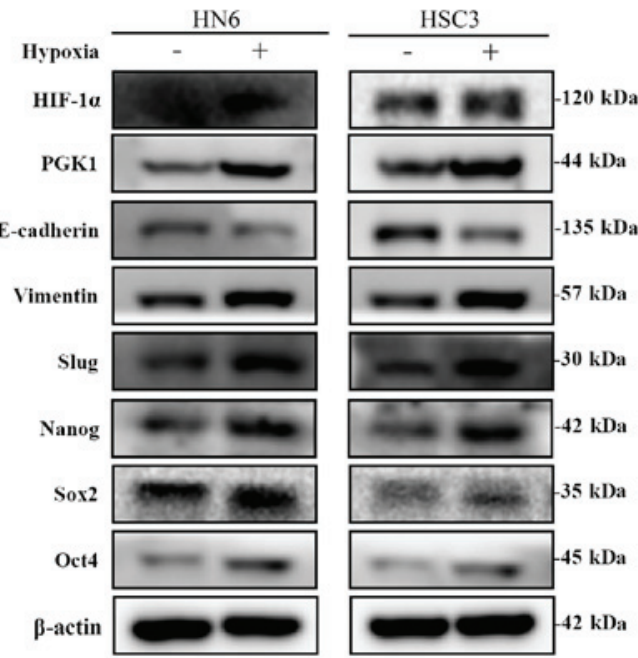

B
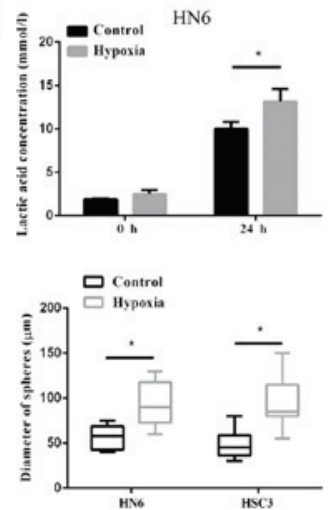

$\mathbf{E}$
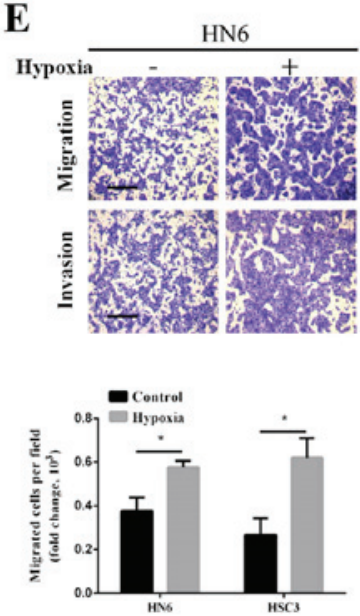
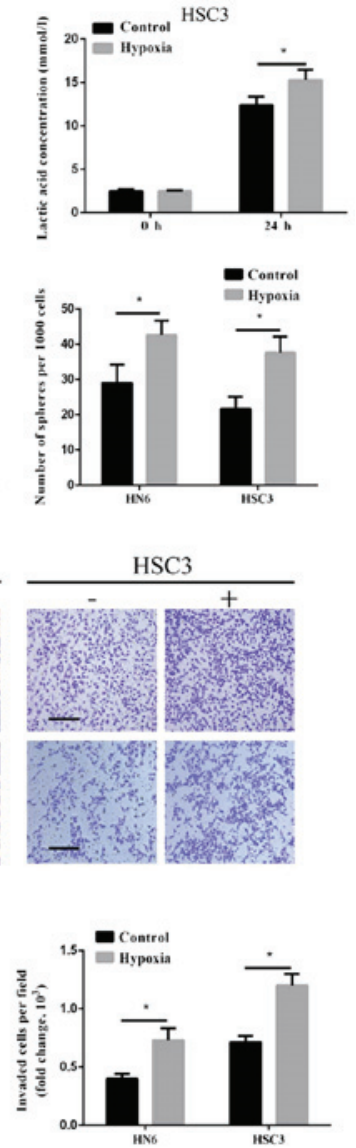

Figure 2. Effects of hypoxia on glycolysis, stem-like properties, migration and invasion of oral squamous cell carcinoma cells. (A) Glucose and (B) lactic acid levels in the culture supernatant of HN6 and HSC3 cells were measured after culturing under hypoxic conditions. (C) Both diameters and numbers of spheres formed by HN6 and HSC3 cells were increased following culturing under hypoxic conditions. Scale bar, $50 \mu \mathrm{m}$. (D) Hypoxic treatment in HN6 and HSC3 cells upregulated the expression PGK1, Sox2, Oct4, Nanog, Vimentin and Slug proteins, whilst reducing the expression of E-cadherin. (E) Transwell assays revealed that hypoxia treatment enhanced the migration and invasion of HN6 and HSC3 cells. ${ }^{*} \mathrm{P}<0.05, \mathrm{n}=3$. Scale bar, $50 \mu \mathrm{m}$. PGK1, phosphoglycerate kinase 1; Sox-2, SRY-box transcription factor 2; Oct4, octamer-binding transcription factor 4; HIF-1 $\alpha$, hypoxia-inducible factor-1 $\alpha$.

squamous cell carcinoma dataset (566 cases) were downloaded from The Cancer Genome Atlas (TCGA) using the UCSC Xena browser (https://xenabrowser.net) (36). In these cases, the primary tumors from the oral cavity (oral cavity, oral tongue, floor of mouth, alveolar ridge, hard palate and buccal mucosa) included 284 oral squamous cell carcinoma specimens and 30 normal oral epithelial tissue samples. The gene expression data and survival results of were analysed using the $\mathrm{R}$ software ( $\mathrm{R}$ version 3.5.3; http://bioconductor.org/biocLite.R) and related R packages, including 'dplyr', 'tidyr', 'ggplot2', and 'survminer' R packages (37-40).

Statistical analysis. Unpaired t-test was used to compare two groups of data and one-way ANOVA followed by Tukey's test was used for multiple comparisons using SPSS version 19.0 (IBM Corp.). $\mathrm{P}<0.05$ was considered to indicate a statistically significant difference. $\chi^{2}$ test was used to evaluate the association between PGK1 expression and the clinicopathological characteristics of patients with OSCC. Wilcoxon signed rank test was used to compare the immunostaining scores between adjacent noncancerous tissue (ANCT) and OSCC. Kruskal-Wallis test followed by Dunn's test was used to compare the immunostaining scores among the OSCC tissues at different stages of differentiation. U Mann-Whitney test was used to compare the immunostaining scores between OSCC tissue specimens with or without lymph node metastasis. The Kaplan-Meier method and log-rank test were used to compare the overall survival of patient. Data were presented as mean \pm SD. Each experiment was performed $\leq 3$ times.

\section{Results}

Hypoxia promotes the proliferation of OSCC cells and increases the expression of PGK1. Oral cancer cell lines HSC3 and HN6 were cultured under hypoxic conditions for 0 , 12 and $24 \mathrm{~h}$, where the results showed that hypoxia for 12 and $24 \mathrm{~h}$ significantly increased cell viability in both oral cancer cell lines (Fig. 1A and B). These findings suggest that hypoxic conditions at appropriate time periods can promote the growth of OSCC cells. There were no significant changes in PGK1 expression in HN6 and HSC3 cells under normal culture conditions at any of the timepoints tested (Fig. 1C and D). In addition, PGK1 expression in HN6 and HSC cells was measured following hypoxia treatment. The results showed that the expression of PGK1 was significantly upregulated 12 and $24 \mathrm{~h}$ following culture under hypoxic conditions (Fig. 1E and F). 
A

HN6

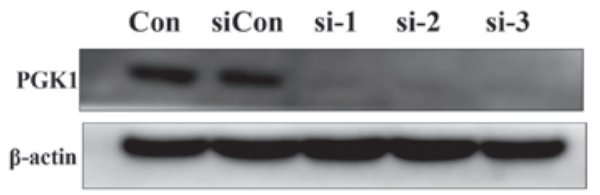

$\begin{array}{lllll}\text { Con } & \text { siCon } & \text { si-1 } & \text { si-2 } & \text { si-3 }\end{array}$

B
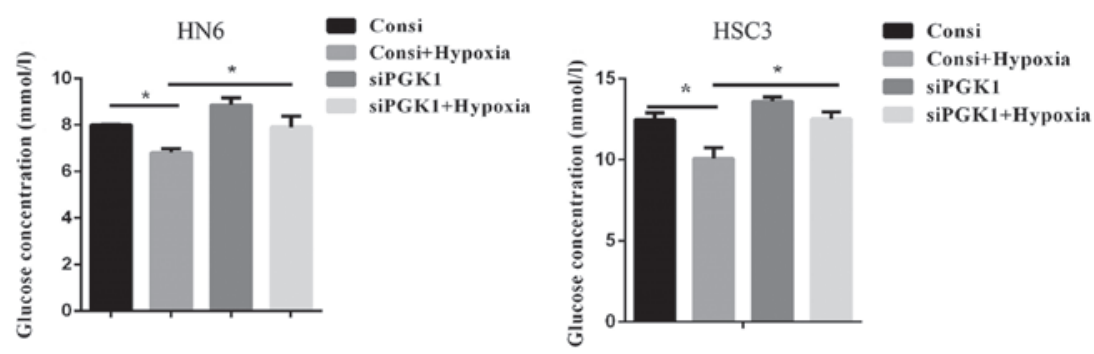

C
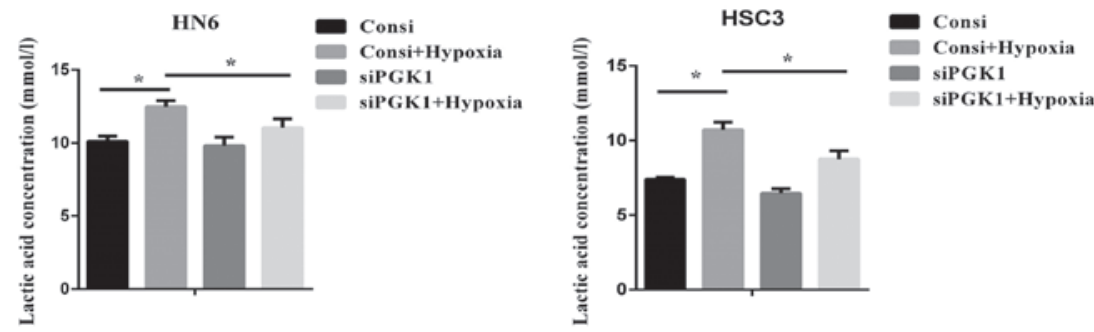

Figure 3. Knockdown of PGK1 expression reverses hypoxia-induced glycolysis. (A) Western blotting was used to measure PGK1 expression in HN6 and HSC3 cells after PGK1 knockdown. Knockdown of PGK1 expression partially reversed the (B) increase in glucose consumption and (C) lactic acid production under hypoxic conditions. "P<0.05, n=3. PGK1, phosphoglycerate kinase 1; si, small interfering RNA; ConsiRNA, control siRNA.

Hypoxia promotes glycolysis, increases stem cell-like properties and enhances OSCC cells migration and invasion. To investigate the effect of hypoxia on the glucose metabolism of OSCC cells, HN6 and HSC3 were cultured under hypoxic conditions for $12 \mathrm{~h}$ followed by incubation under normoxic conditions for $12 \mathrm{~h}$. Glucose consumption and lactic acid production were found to be significantly higher in cells cultured under hypoxic conditions compared with cells cultured under normoxic conditions (Fig. 2A and B). These findings suggest that hypoxia may promote glycolysis in OSCC cells. The effects of hypoxia on OSCC cell invasion and migration, in addition to the expression of stem cell markers, were subsequently examined. It was found that the diameter and number of spheroids formed were significantly higher in cells incubated under hypoxic conditions compared with cells cultured under normoxic conditions (Fig. 2C). Hypoxia treatment was also revealed to upregulate the expression of stem cell markers Sox2, Oct4 and Nanog in HN6 and HSC3 cells (Fig. 2D). In addition, the expression levels of PGK1, in addition to those of vimentin and slug, were found to be upregulated following culture under hypoxic conditions compared with cells cultured under normoxic conditions (Fig. 2D). By contrast, E-cadherin expression was revealed to be lower compared with that in normoxic cells (Fig. 2D). Since EMT is a key process in potentiating tumour migration and invasion (7), the role of hypoxia in the invasion and migration of OSCC cells was assessed by Transwell assays. Hypoxia was found to significantly enhance HN6 and HSC3 cell migration and invasion compared with normoxic cells (Fig. 2E).
PGK1 knockdown reverses the effects of hypoxia on glucose consumption, stem cell-like characteristics and EMT in OSCC cells. To study the effect of hypoxia treatment on OSCC cells after PGK1 knockdown, the effect of siRNA transfection on the PGK1 expression under normoxic conditions was first verified by western blotting (Fig. 3A). PGK1 knockdown using PGK si-01 was found to partially but significantly reverse the positive effects of hypoxia on glucose consumption (Fig. 3B) and lactic acid production (Fig. 3C). In terms of EMT, PGK1 knockdown markedly reversed the increases in the expression of EMT markers vimentin and Slug whilst markedly preventing the reduction in E-cadherin caused by hypoxia (Fig. 4A). PGK1 knockdown did not significantly affect HIF-1 $\alpha$ expression, which was upregulated by hypoxia (Fig. 4A). PGK1 knockdown was found to markedly suppress the expression of stem cell markers Sox 2, Oct4 and Nanog in addition to reversing the hypoxia-induced upregulation of these stem cell markers (Fig. 4A). Under hypoxic conditions, silencing PGK1 expression also significantly inhibited cell migration and invasion (Fig. 4A and C), whilst also significantly reducing the diameter and number of spheres formed by HN6 and HSC3 cells compared with those transfected with control siRNA (Fig. 4A and B).

PGK1 knockdown inhibits tumour growth whereas the upregulation of PGK1 expression promotes tumour growth in vivo. To study the effect of PGK1 on the phenotype of OSCC tumours in vivo, pre-constructed HSC3 PGK1 knockout (shPGK1) or overexpression cell lines were injected into the subcutaneous tissues of SCID mice. Tumour volumes and weights were 
A

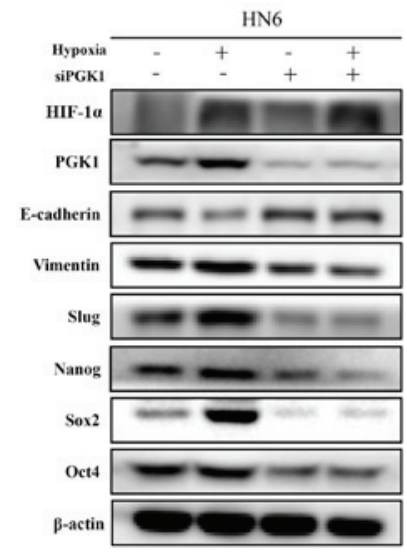

B
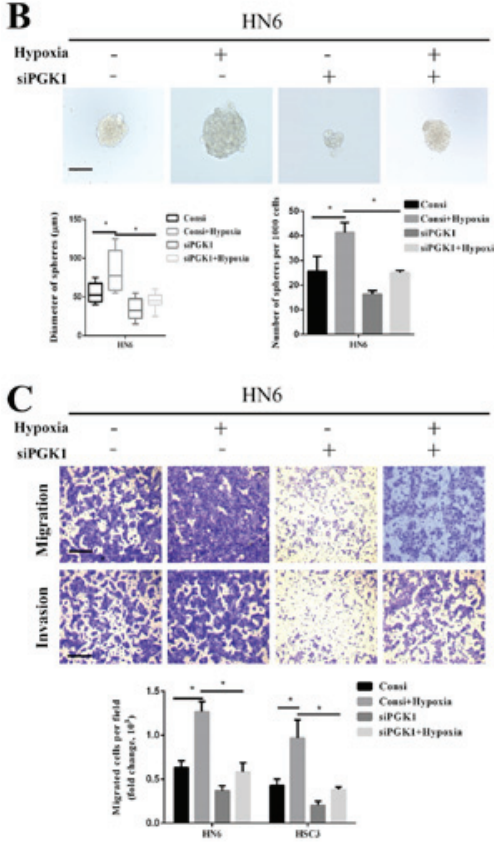
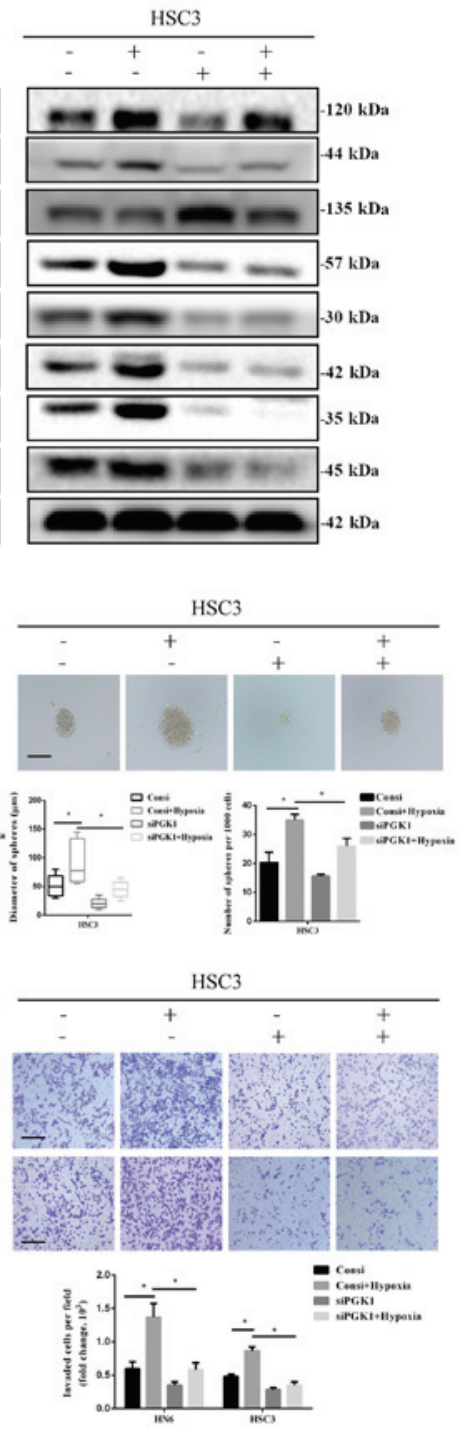

Figure 4. Knockdown of PGK1 expression reverses hypoxia-activated stem-like properties and epithelial-mesenchymal transition in oral squamous cell carcinoma cells. (A) HN6 and HSC3 cells were treated under hypoxic conditions and/or transfected with siPGK1, following which the expression of the indicated proteins was measured by western blotting. (B) Sizes and numbers of spheroids formed were measured after HN6 and HSC3 cells were cultured under hypoxic conditions and/or transfected with siPGK1. Spheroids with diameters $>50 \mu \mathrm{m}$ were displayed. Scale bar, $50 \mu \mathrm{m}$. (C) Transwell assays were used to measure HN6 and HSC3 cell migration and invasion following culturing under hypoxic conditions and/or transfection with siPGK1. ${ }^{*} \mathrm{P}<0.05$, $\mathrm{n}=3$. Scale bar, $50 \mu \mathrm{m}$. PGK1, phosphoglycerate kinase 1; Sox-2, SRY-box transcription factor 2; Oct4, octamer-binding transcription factor 4; HIF-1 $\alpha$, hypoxia-inducible factor-1 $\alpha$; si, small interfering RNA; ConsiRNA, control siRNA.

found to be significantly reduced in the group injected with cells transfected shPGK1 with compared with those injected with cells transfected with the shVector 1 month after injection (Fig. 5A). By contrast, tumour volumes and weights were demonstrated to be significantly increased in the group transfected with cells overexpressing PGK1 compared with those injected with cells transfected with the vector (Fig. 5A). Furthermore, compared with those in the PGK1 overexpression group, mice in the shPGK1 group also exhibited markedly lower levels of PGK1, vimentin, Slug, Sox2, Oct4 and Nanog expression, whilst showing higher levels of E-cadherin expression (Fig. 5B and C).

PGK1 promotes stem cell-like properties and EMT in OSCC cells through the AKT signalling pathway. The activity of the AKT signalling pathway was next measured in OSCC cells under normoxic conditions. PGK1 knockdown was found to reduce p-AKT phosphorylation (Fig. 6A). SC79, an activator of AKT, was used to investigate the effects of the AKT signalling pathway on PGK1-mediated stemness and EMT in OSCC cells, also under normoxic condtions. SC79 treatment was revealed to increase AKT phosphorylation whilst reversing the inhibitory effects of PGK1 knockdown on vimentin, Slug, Sox2, Oct4 and Nanog expression (Fig. 6B). In addition, increases in E-cadherin expression induced by PGK1 knockdown was also found to be reversed by SC79 treatment (Fig. 6B). SC79 was found to promote significantly potentiate sphere formation, migration and invasion in HN6 and HSC3 cells following PGK1 knockdown (Fig. 6C and D). These findings suggest that PGK1 may promote OSCC stemness and EMT by activating the AKT signalling pathway.

PGK1 expression is correlated with clinicopathological features in patients with OSCC. To clarify if the levels of PGK1 

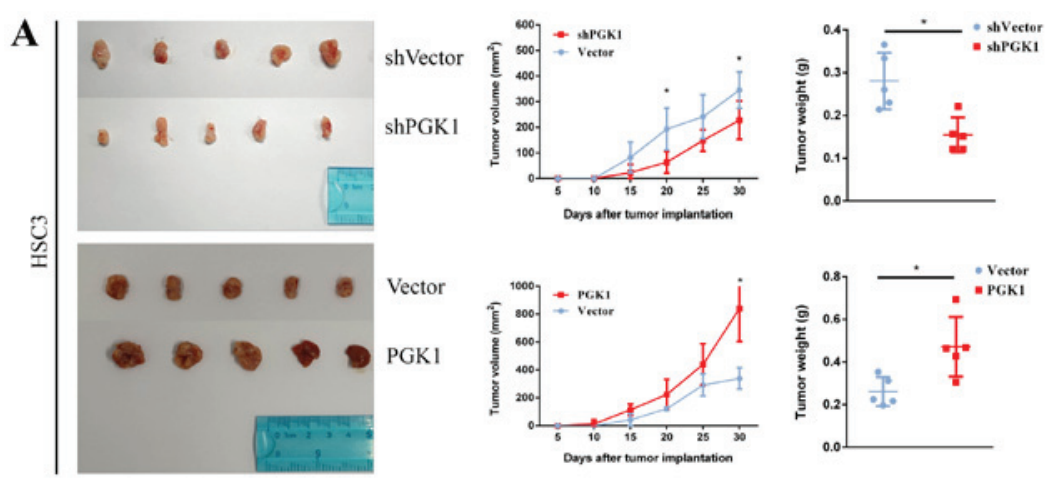

B
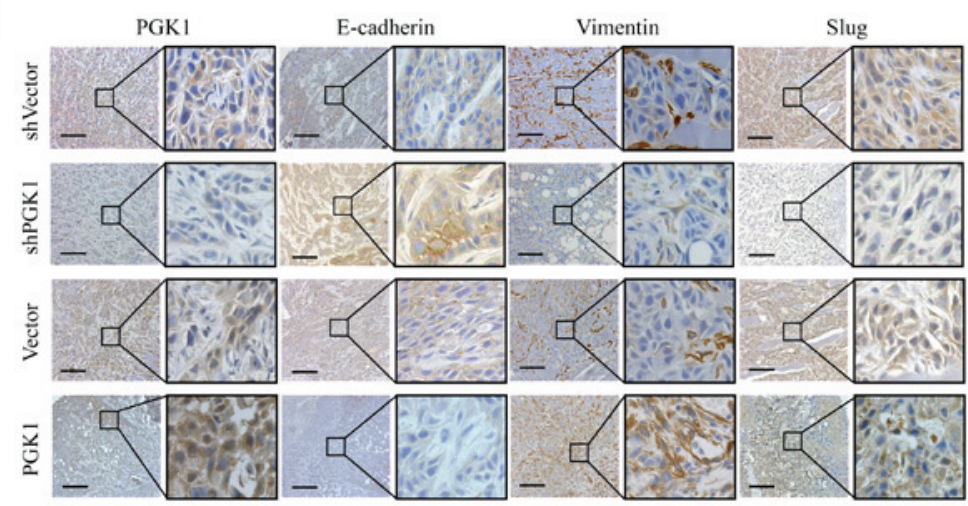

C

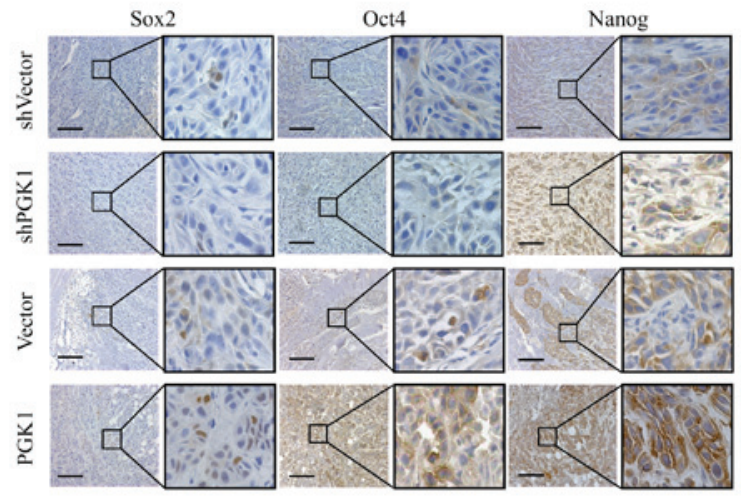

Figure 5. PGK1 knockdown inhibits tumour growth whereas the PGK1 upregulation promotes tumour growth in vivo. (A) Images of the tumours isolated from mice in the shVector, shPGK1 and Vector and PGK1 groups. Volume of the tumours over 30 days, in addition to the weight of the tumours following euthanasia, were measured. Representative IHC images showing the staining of (B) epithelial-mesenchymal transition and (C) stem cell markers in the tumour xenografts isolated from each of the four groups. "P $<0.05, \mathrm{n}=5$. Scale bar, $50 \mu \mathrm{m}$. IHC, immunohistochemistry; PGK1, phosphoglycerate kinase 1; sh, short hairpin RNA.

expression is associated with the clinicopathological characteristics of patients with OSCC, PGK1 expression was measured in tissue samples obtained from 92 patients with OSCC and 20 ANCT specimens by immunohistochemistry (Fig. 7A). Semi-quantitative analysis showed that the PGK1 expression in OSCC specimens was significantly higher compared with that in ANCT (Fig. 7B). Compared with that in well-differentiated OSCC tissue samples, PGK1 expression was found to be significantly higher in moderately and poorly differentiated OSCC tissues (Fig. 7C). PGK1 expression was also demonstrated to be significantly higher in OSCC tissue specimens with lymph node metastasis compared with that in OSCC specimens without lymph node metastasis (Fig. 7D). The relationship between PGK1 expression and the clinicopathological characteristics of patients with OSCC was next examined. PGK1 expression was found to significantly associate with tumour differentiation, clinical staging and lymph node metastasis, but not with age, sex or T stage (Table I).
PGK1 expression levels in patients with OSCC patients is associated with survival and prognosis. The levels of PGK1 expression was next compared between 284 OSCC samples and 30 normal oral mucosal epithelial tissue samples obtained from the TCGA database. PGK1 expression was revealed to be significantly upregulated in OSCC samples compared with that in the normal oral mucosal epithelial tissue samples (Fig. 8A). Survival analysis showed that the overall survival rate of patients with high expression of PGK1 was significantly reduced compared with those with low PGK1 expression (Fig. 8B).

\section{Discussion}

Strong invasive and migratory capacities are among the main causes underlying oral cancer cell metastasis, which is particularly prone to metastasizing to cervical lymph nodes and distant organs, significantly reducing the quality of life of patients (41-43). 
$\mathbf{A}$

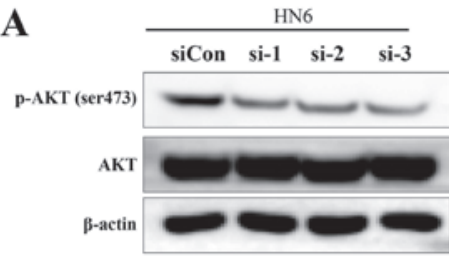

B

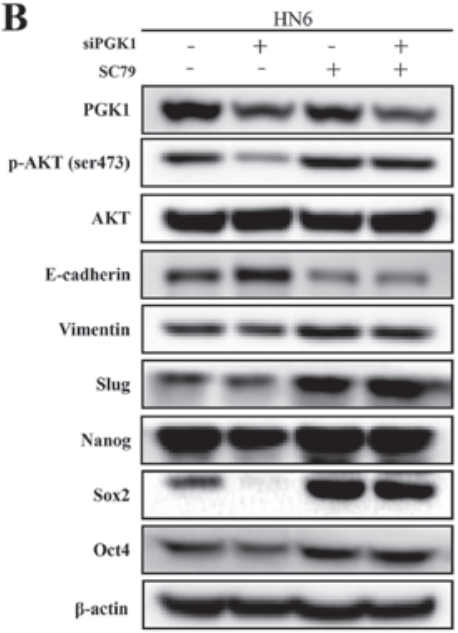

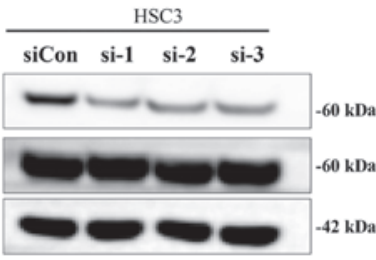

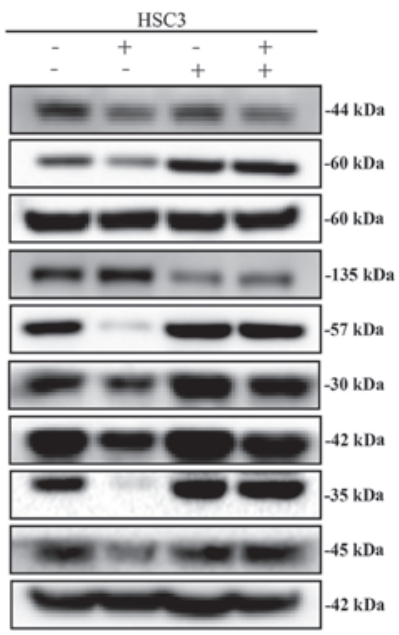

C
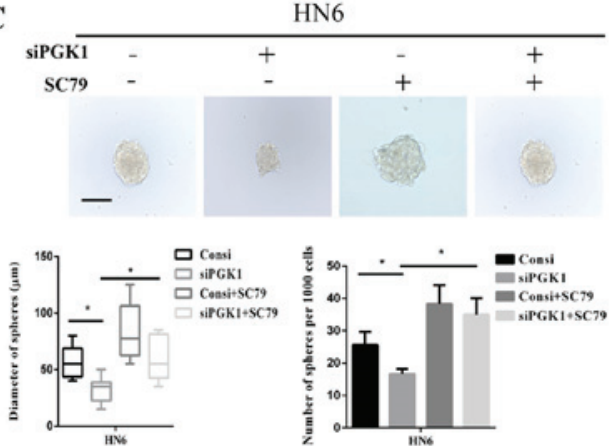

D
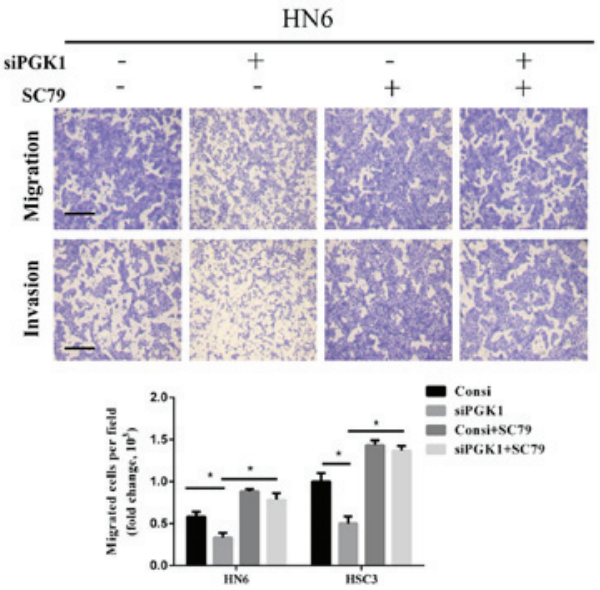
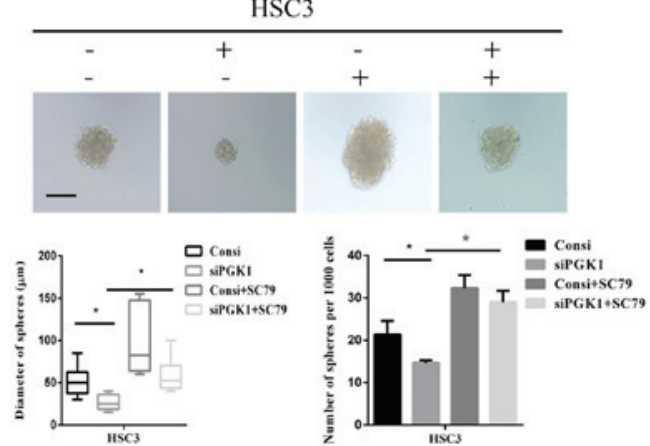

HSC3
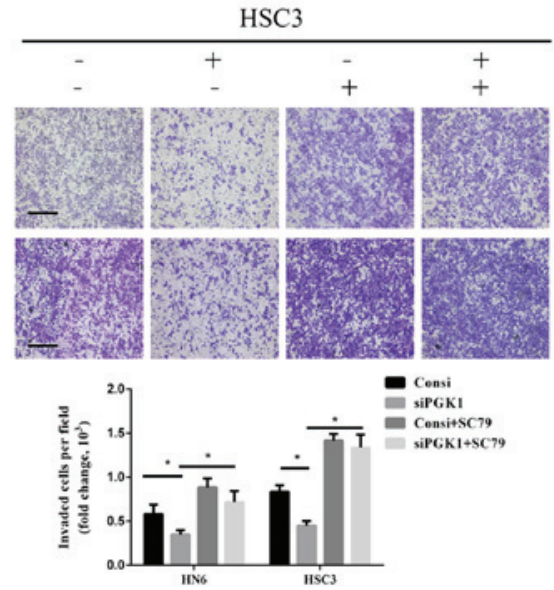

Figure 6. PGK1 promotes stem-like properties and epithelial-mesenchymal transition in oral squamous cell carcinoma cells through the AKT signalling pathway. (A) Western blotting was used to measure the phosphorylation of AKT in HN6 and HSC3 cells after PGK1 knockdown. (B) HN6 and HSC3 cells were treated with SC79 and/or transfected with siPGK1, following which the expression levels of the indicated proteins were measured by western blotting. (C) Sizes and numbers of spheroids formed were measured after HN6 and HSC3 cells were treated with SC79 and/or transfected with siPGK1. Spheroids with diameters $>50 \mu \mathrm{m}$ were displayed. Scale bar, $50 \mu \mathrm{m}$. (D) Transwell assays were used to measure HN6 and HSC3 cell migration and invasion following treatment with SC79 and/or transfection with siPGK1. ${ }^{*} \mathrm{P}<0.05, \mathrm{n}=3$. Scale bar, $50 \mu \mathrm{m}$. PGK1, phosphoglycerate kinase 1; Sox-2, SRY-box transcription factor 2; Oct4, octamer-binding transcription factor 4; HIF-1 $\alpha$, hypoxia-inducible factor-1 $\alpha$; si, small interfering RNA; ConsiRNA, control siRNA.

Cell division and proliferation are metabolically active processes within cells. However, energy production within cancer cells does not particularly depend on the classical oxidative phosphorylation pathway performed by 
Table I. Association between PGK1 expression and clinicopathological features in patients with OSCC ( $\mathrm{n}=92)$.

\begin{tabular}{|c|c|c|c|c|}
\hline \multirow[b]{2}{*}{ Clinicopathological features } & \multirow[b]{2}{*}{ No. of cases } & \multicolumn{2}{|c|}{ PGK1 expression } & \multirow[b]{2}{*}{ P-value } \\
\hline & & $\operatorname{High}(\mathrm{n})$ & Low $(\mathrm{n})$ & \\
\hline Sex & & & & 0.052 \\
\hline Male & 58 & 36 & 22 & \\
\hline Female & 34 & 14 & 20 & \\
\hline Age & & & & 0.809 \\
\hline$\geq 55$ & 56 & 31 & 25 & \\
\hline$<55$ & 36 & 19 & 17 & \\
\hline Differentiation & & & & 0.001 \\
\hline Well & 16 & 4 & 12 & \\
\hline Moderate + poor & 76 & 46 & 30 & \\
\hline T stage & & & & 0.107 \\
\hline T1-2 & 77 & 39 & 38 & \\
\hline T3-4 & 15 & 11 & 4 & \\
\hline Clinical stage & & & & 0.008 \\
\hline I-II & 59 & 26 & 33 & \\
\hline III-IV & 33 & 24 & 9 & \\
\hline LN metastasis & & & & 0.018 \\
\hline $\mathrm{N}^{-}$ & 68 & 32 & 36 & \\
\hline $\mathrm{N}^{+}$ & 24 & 18 & 6 & \\
\hline
\end{tabular}

$\mathrm{N}^{-}$, no lymph node metastasis; $\mathrm{N}^{+}$, presence of lymph node metastasis.
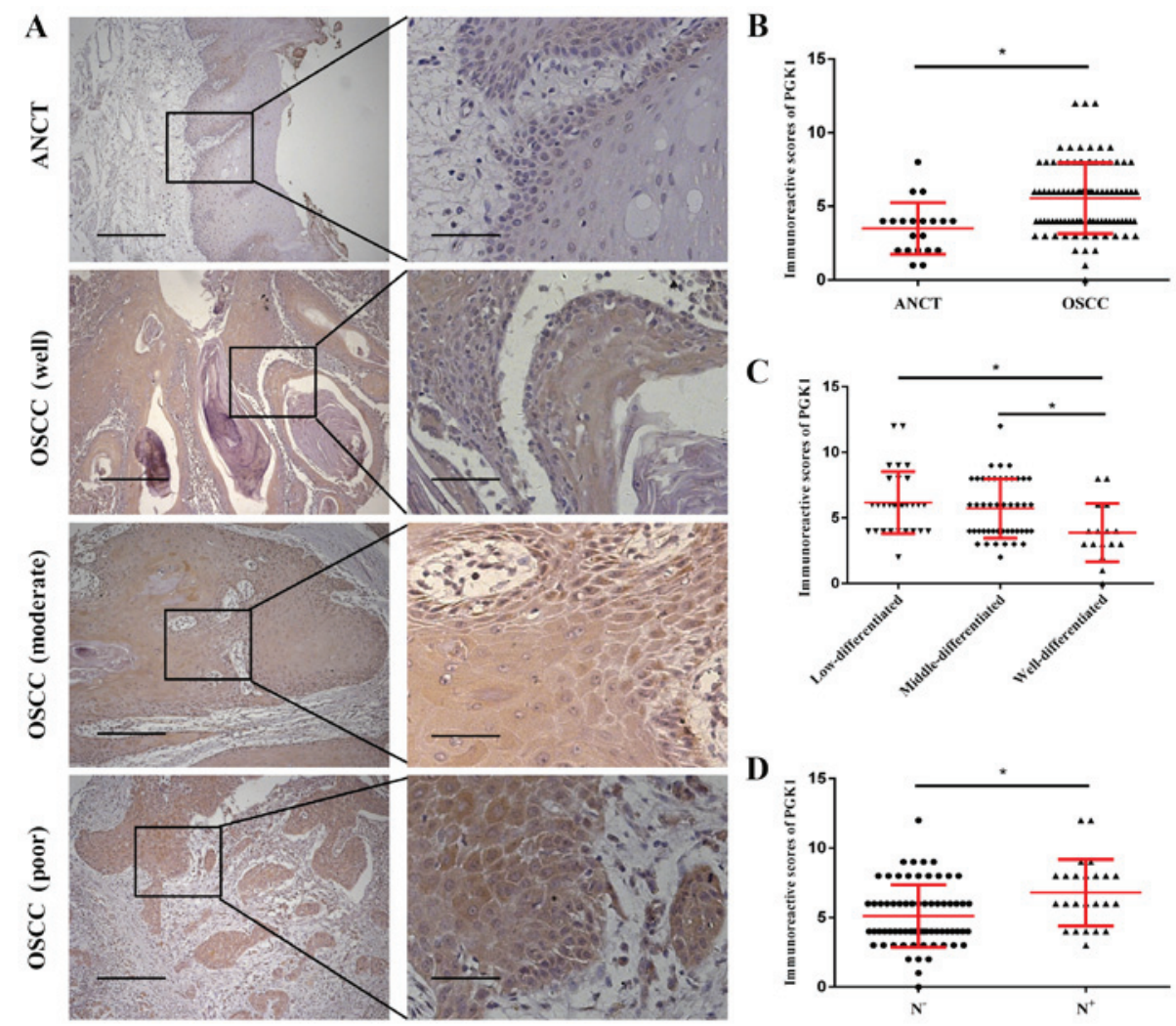

Figure 7. PGK1 expression in OSCC samples. (A) Representative immunohistochemistry images showing that the expression of PGK1 in OSCC specimens at three different stages of differentiation was higher compared with that in ANCT. (B) Comparison of PGK1 expression between OSCC and adjacent noncancerous tissue samples. (C) PGK1 expression is higher in moderately and poorly differentiated OSCC tissues. (D) PGK1 expression is higher in OSCC tissue specimens with lymph node metastasis. " $\mathrm{P}<0.05$. Scale bar, $50 \mu \mathrm{m}$ (left), $10 \mu \mathrm{m}$ (right). OSCC, oral squamous cell carcinoma; ANCT, adjacent noncancerous tissue samples; $\mathrm{N}^{-}$, no lymph node metastasis; $\mathrm{N}^{+}$, presence of lymph node metastasis; PGK1, phosphoglycerate kinase 1. 
A

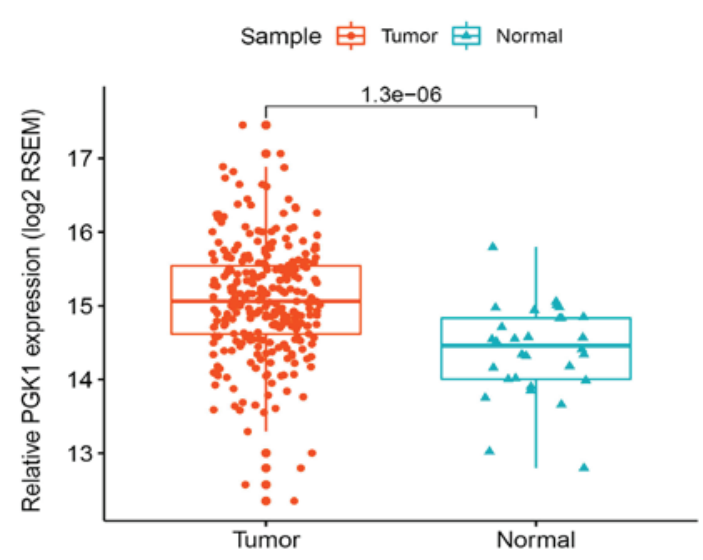

B

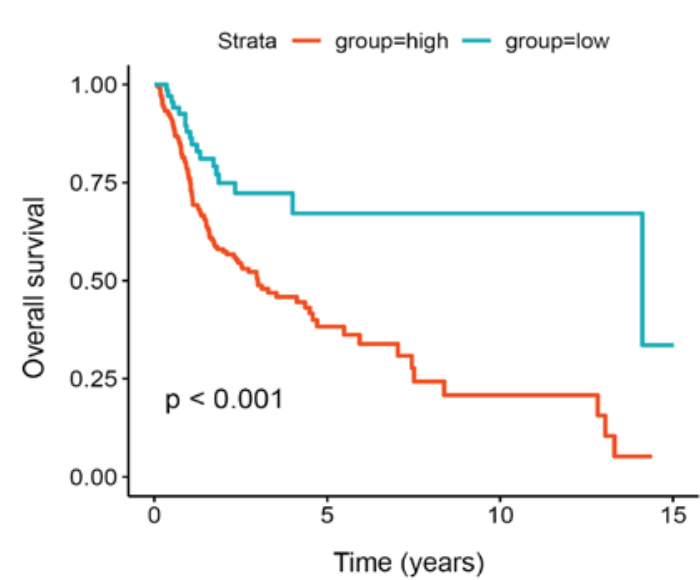

Figure 8. Expression levels of PGK1 in patients with OSCC is associated with overall survival and prognosis. (A) PGK1 mRNA expression in OSCC $(n=284)$ and ANCT $(n=30)$ samples collected from the TCGA database. (B) Kaplan-Meier survival curves for overall survival in OSCC. OSCC, ora squamous cell carcinoma; ANCT, adjacent noncancerous tissue samples; PGK1, phosphoglycerate kinase 1 .

mitochondria (44). On the contrary, cancer cells frequently utilize the glycolytic pathway to produce ATP, even when the supply of oxygen is sufficient. This is a process known as the 'Warburg effect' (45). A previous study has found that glutamine starvation can activate PFKP expression, whilst downregulation of PFKP can reverse the invasion and migration of OSCC cells induced by starvation (46). In addition, previous studies have documented that hypoxia is closely associated with tumorigenesis, cell development, invasion and migration in oral cancer $(47,48)$.

Hypoxic environments can be readily found in solid malignant tumors and can lead to alterations in the expression of a number of molecular biomarkers, including HIF, carbonic anhydrase, glucose-transporter-1 and vascular endothelial growth factor (49). HIF-1 $\alpha$, which is activated under hypoxic conditions, is involved in the regulation of tumor cell propagation, migration, glucose metabolism and angiogenesis (50). It allows cells to adapt to hypoxic environments, contributing to invasion and metastasis. It was previously found that HIF-1 $\alpha$ can promote the malignant progression of esophageal squamous cell carcinoma by regulating the expression specificity protein 1 (49). In the present study, it was found that both HIF-1 $\alpha$ and PGK1 expression were upregulated due to hypoxia, suggesting an association between these two proteins.

PGK1 is a key enzyme in glycolysis, which converts glyceric acid 1,3-diphosphate to produce glyceric acid 3-phosphate and ATP (28). A number of studies previously found that PGK1 expression is significantly associated with the survival and prognosis of patients with hepatocellular carcinoma, where PGK1 knockdown can inhibit the proliferation of hepatocellular carcinoma cell lines $(50,51)$. PGK1 expression in several tumour tissues was found to be higher compared with that in normal tissues (26), whilst HIF-1 $\alpha$ has been previously shown to directly regulate PGK1 (52). In liver cancer, the expression levels of PGK1 and HIF-1 $\alpha$ in the hepatocellular carcinoma cell line HCCLM9 with high metastasis were higher when compared with those in the hepatocellular carcinoma cell line MHCC97L with low metastasis $(26,33)$, such that PGK1 has also been revealed to regulate cell proliferation and metastasis (32). In addition, PGK1 expression was found to correlate with the survival and prognosis of patients with breast cancer (53). PGK1 overexpression can promote the development and metastasis of gastric cancer by activating the $\mathrm{C}-\mathrm{X}-\mathrm{C}$ motif chemokine receptor $4 / \mathrm{C}-\mathrm{X}-\mathrm{C}$ motif chemokine $12 / \beta$-catenin signalling pathway (26). The present study found that $12 \mathrm{~h}$ of hypoxia treatment could promote the proliferation of oral cancer cells. The present study also found that hypoxic conditions upregulated the expression of PGK1 and stem cell markers in OSCC cell lines.

EMT is a key mechanism for potentiating invasion and migration in OSCC cells, where the self -renewing and proliferative capacities of tumor stem cells is one of the causes of OSCC recurrence. It has been previously demonstrated that the differential expression of stem cell markers, including CD44, CD133 and ALDH1, in addition to transcription factors, including Oct4, Sox 2 and Nanog, serve an important role in clonogenesis in oral squamous cell carcinomas $(54,55)$. In the present study, hypoxia was shown to upregulate the expression of EMT markers promote the migration and invasion of oral cancer cells. Further investigation found that PGK1 knockdown partially reversed the invasion and migration of oral cancer cells under hypoxic conditions.

The AKT signalling pathway is involved in many processes, including proliferation, apoptosis, cancer cell migration and invasion (56). Aberrant activation of the AKT signalling pathway has been previously shown to serve an important role in the malignant progression of cancer $(57,58)$. A previous study has demonstrated that the $\mathrm{AKT} / \mathrm{NF} \mathrm{B}$ signalling pathway is involved in the invasion and migration of lung cancer cells, which is closely associated with the maintenance of stem cell characteristics and EMT (59). Another study has also previously found that hypoxia promotes glioma cell proliferation, migration and invasion via PI3K/AKT signalling (58). Results from the present study suggest that the downregulation of PGK1 inhibits the phosphorylation of AKT, whilst the AKT activator SC79 reversed the effects observed following PGK1 knockdown.

Differential observations would have been made if the present study was performed under hypoxic conditions compared with cells grown under normoxic conditions. 
A preliminary study of the present study found that following hypoxia treatment for $>48 \mathrm{~h}$, the cells were in a poor state of health and could not complete the subsequent proliferation, invasion and migration experiments. Therefore, the method of hypoxia pre-treatment was applied to study the effects of hypoxia on the biological behaviour of tumour cells. The results demonstrated that appropriate hypoxia can promote the malignant progress of OSCC cells, where further study found that moderate hypoxia can promote tumour cell proliferation. This was a limitation of the present study, which remain to be the focus of future research.

To conclude, data from the present study suggest that hypoxia can upregulate PGK1 expression and glycolysis whilst activating the characteristics of oral cancer stem cells and EMT through the AKT pathway. However, the exact mechanism require further clarification.

\section{Acknowledgements}

Not applicable.

\section{Funding}

The present study was supported by the National Natural Science Foundation project of China (grant nos. 81874128 and 81572660) and Sun Yat-Sen University Clinical Research 5010 Program (grant no. 2015018).

\section{Availability of data and materials}

All data generated or analyzed during this study are included in this article.

\section{Authors' contributions}

JH developed the concept of the project. YZ designed and performed the experiments, analysed the results and wrote the manuscript. HC performed the immunohistochemical staining. YL collected and analysed clinical specimens and clinical data. FW and YZ were involved in statistical analysis of the obtained results. All authors read and approved the final version of the manuscript.

\section{Ethics approval and consent to participate}

The removal of tissue samples from patients was approved by the ethical review committee of the Affiliated Stomatological Hospital of Sun Yat-sen University (Guangzhou, China). The experiments were performed with the understanding and written consent of each subject. The study methodologies conformed to the standards set by the Declaration of Helsinki.

\section{Patient consent for publication}

Not applicable.

\section{Competing interests}

The authors declare that they have no competing interests.

\section{References}

1. Massano J, Regateiro FS, Januário G and Ferreira A: Oral squamous cell carcinoma: Review of prognostic and predictive factors. Oral Surg Oral Med Oral Pathol Oral Radiol Endod 102: 67-76, 2006.

2. Rajwar YC, Jain N, Bhatia G, Sikka N, Garg B and Walia E: Expression and Significance of Cadherins and Its Subtypes in Development and Progression of Oral Cancers: A Review. J Clin Diagn Res 9: ZE05-ZE07, 2015.

3. Chang WC, Chang CF, Li YH, Yang CY, Su RY, Lin CK and Chen YW: A histopathological evaluation and potential prognostic implications of oral squamous cell carcinoma with adverse features. Oral Oncol 95: 65-73, 2019.

4. Huang Z, Xie N, Liu H, Wan Y, Zhu Y, Zhang M, Tao Y, Zhou H, Liu X, Hou J and Wang C: The prognostic role of tumour-infiltrating lymphocytes in oral squamous cell carcinoma: A meta-analysis. J Oral Pathol Med 48: 788-798, 2019.

5. Siegel RL, Miller KD and Jemal A: Cancer statistics, 2016. CA Cancer J Clin 66: 7-30, 2016.

6. Kademani D, Bell RB, Schmidt BL, Blanchaert R, Fernandes R. Lambert P and Tucker WM; American Association of Oral and Maxillofacial Surgeons Task Force on Oral Cancer: Oral and maxillofacial surgeons treating oral cancer: a preliminary report from the American Association of Oral and Maxillofacial Surgeons Task Force on Oral Cancer. J Oral Maxillofac Surg 66: 2151-2157, 2008.

7. Xie Y, Zhong L, Duan D and Li T: Casticin inhibits invasion and proliferation via downregulation of $\beta$-catenin and reversion of EMT in oral squamous cell carcinoma. J Oral Pathol Med 48: 897-905, 2019.

8. Staton CA, Brown NJ and Reed MW: Current status and future prospects for anti-angiogenic therapies in cancer. Expert Opin Drug Discov 4: 961-979, 2009.

9. Bergers $\mathrm{G}$ and Benjamin LE: Tumorigenesis and the angiogenic switch. Nat Rev Cancer 3: 401-410, 2003.

10. Klymkowsky MW and Savagner P: Epithelial-mesenchymal transition: A cancer researcher's conceptual friend and foe. Am J Pathol 174: 1588-1593, 2009.

11. Thiery JP, Acloque H, Huang RY and Nieto MA: Epithelial-mesenchymal transitions in development and disease. Cell 139: 871-890, 2009.

12. Wang C, Liu X, Chen Z, Huang H, Jin Y, Kolokythas A, Wang A, Dai Y, Wong DT and Zhou X: Polycomb group protein EZH2-mediated E-cadherin repression promotes metastasis of oral tongue squamous cell carcinoma. Mol Carcinog 52: 229-236, 2013

13. Dawei H, Honggang D and Qian W: AURKA contributes to the progression of oral squamous cell carcinoma (OSCC) through modulating epithelial-to-mesenchymal transition (EMT) and apoptosis via the regulation of ROS. Biochem Biophys Res Commun 507: 83-90, 2018.

14. Zhang J, Zheng G, Zhou L, Li P, Yun M, Shi Q, Wang T and Wu X: Notch signalling induces epithelial mesenchymal transition to promote metastasis in oral squamous cell carcinoma. Int J Mol Med 42: 2276-2284, 2018.

15. Krisanaprakornkit S and Iamaroon A: Epithelial-mesenchymal transition in oral squamous cell carcinoma. ISRN Oncol 2012: 681469, 2012.

16. Espinoza I and Miele L: Deadly crosstalk: Notch signaling at the intersection of EMT and cancer stem cells. Cancer Lett 341: 41-45, 2013.

17. Costa LC, Leite CF, Cardoso SV, Loyola AM, Faria PR, Souza PE and Horta MC: Expression of epithelial-mesenchymal transition markers at the invasive front of oral squamous cell carcinoma. J Appl Oral Sci 23: 169-178, 2015.

18. Tran Q, Lee H, Park J, Kim SH and Park J: Targeting Cancer Metabolism - Revisiting the Warburg Effects. Toxicol Res 32: 177-193, 2016.

19. Wu CA, Chao Y, Shiah SG and Lin WW: Nutrient deprivation induces the Warburg effect through ROS/AMPK-dependent activation of pyruvate dehydrogenase kinase. Biochim Biophys Acta 1833: 1147-1156, 2013

20. Sasabe E, Tatemoto Y,Li D, Yamamoto T and Osaki T: Mechanism of HIF-1alpha-dependent suppression of hypoxia-induced apoptosis in squamous cell carcinoma cells. Cancer Sci 96: 394-402, 2005.

21. Cheng ZX, Sun B, Wang SJ, Gao Y, Zhang YM, Zhou HX, Jia G, Wang YW, Kong R, Pan SH, et al: Nuclear factor- $\kappa$ B-dependent epithelial to mesenchymal transition induced by HIF-1 $\alpha$ activation in pancreatic cancer cells under hypoxic conditions. PLoS One 6: e23752, 2011. 
22. Joseph JP, Harishankar MK, Pillai AA and Devi A: Hypoxia induced EMT: A review on the mechanism of tumor progression and metastasis in OSCC. Oral Oncol 80: 23-32, 2018.

23. Zheng M, Cao MX, Luo XJ, Li L, Wang K, Wang SS, Wang HF, Tang YJ, Tang YL and Liang XH: EZH2 promotes invasion and tumour glycolysis by regulating STAT3 and FoxO1 signalling in human OSCC cells. J Cell Mol Med 23: 6942-6954, 2019.

24. Liang J, Cao R, Zhang Y, Xia Y, Zheng Y, Li X, Wang L, Yang $\mathrm{W}$ and Lu Z: PKM2 dephosphorylation by Cdc25A promotes the Warburg effect and tumorigenesis. Nat Commun 7: 12431, 2016.

25. Valentin C, Birgens H, Craescu CT, Brødum-Nielsen K and Cohen-Solal M: A phosphoglycerate kinase mutant (PGK Herlev; D285V) in a Danish patient with isolated chronic hemolytic anemia: Mechanism of mutation and structure-function relationships. Hum Mutat 12: 280-287, 1998.

26. He Y, Luo Y, Zhang D, Wang X, Zhang P, Li H, Ejaz S and Liang S: PGK1-mediated cancer progression and drug resistance. Am J Cancer Res 9: 2280-2302, 2019.

27. Beutler E: PGK deficiency. Br J Haematol 136: 3-11, 2007.

28. Morales-Briceño H, Ha AD, London K, Farlow D, Chang FCF and Fung VSC: Parkinsonism in PGK1 deficiency implicates the glycolytic pathway in nigrostriatal dysfunction. Parkinsonism Relat Disord 64: 319-323, 2019.

29. Hogrel JY, Ledoux I and Béhin A: Hyperammonaemia following exercise may also reveal PGK1 deficiency. J Clin Pathol 72: 452, 2019.

30. Echaniz-Laguna A, Nadjar Y, Béhin A, Biancalana V, Piraud M, Malfatti E and Laforêt P: Phosphoglycerate kinase deficiency: A nationwide multicenter retrospective study. J Inherit Metab Dis 42: 803-808, 2019.

31. McCarrey JR, Kumari M, Aivaliotis MJ, Wang Z, Zhang P, Marshall $F$ and Vandeberg JL: Analysis of the cDNA and encoded protein of the human testis-specific PGK-2 gene. Dev Genet 19: 321-332, 1996.

32. Xie H, Tong G, Zhang Y, Liang S, Tang K and Yang Q: PGK1 Drives Hepatocellular Carcinoma Metastasis by Enhancing Metabolic Process. Int J Mol Sci 18: 18, 2017.

33. Shao F, Yang X, Wang W, Wang J, Guo W, Feng X, Shi S, Xue Q, Gao S, Gao Y, et al: Associations of PGK1 promoter hypomethylation and PGK1-mediated PDHK1 phosphorylation with cancer stage and prognosis: A TCGA pan-cancer analysis. Cancer Commun (Lond) 39: 54, 2019.

34. Zhou JW, Tang JJ, Sun W and Wang H: PGK1 facilities cisplatin chemoresistance by triggering HSP90/ERK pathway mediated DNA repair and methylation in endometrial endometrioid adenocarcinoma. Mol Med 25: 11, 2019.

35. Balch CM, Gershenwald JE, Soong SJ, Thompson JF, Atkins MB, Byrd DR, Buzaid AC, Cochran AJ, Coit DG, Ding S, et al: Final version of 2009 AJCC melanoma staging and classification. J Clin Oncol 27: 6199-6206, 2009.

36. Goldman M, Craft B, Kamath A, Brooks A, Zhu J and Haussler D The UCSC Xena Platform for cancer genomics data visualization and interpretation. bioRxiv: https://doi.org/10.1101/326470,2018.

37. Wickham H: Tidy Data. J Stat Softw 59: 10, 2014.

38. Wickham H: ggplot2: Elegant Graphics for Data Analysis. Springer-Verlag, New York, NY, 2009.

39. Kassambara A, Kosinski M, Przemyslaw B and Scheipl F: Drawing survival curves using 'ggplot2'. http://cran.r-project.org/ package $=$ survminer. Accessed May 28, 2020.

40. Wickham H, François R, Henry L, Müller K and RStudio: dplyr: A Grammar of Data Manipulation. R Package Version 0.3.0.2. https:// cran.r-project.org/web/packages/dplyr/index.html. Accessed May 29, 2020.

41. Warnakulasuriya S: Living with oral cancer: Epidemiology with particular reference to prevalence and life-style changes that influence survival. Oral Oncol 46: 407-410, 2010.
42. Eckert AW, Kappler M, Schubert J and Taubert H: Correlation of expression of hypoxia-related proteins with prognosis in oral squamous cell carcinoma patients. Oral Maxillofac Surg 16: 189-196, 2012.

43. Adeyemi BF and Kolude B: Clinical presentation of oral squamous cell carcinoma. Niger Postgrad Med J 20: 108-110, 2013.

44. Hsu PP and Sabatini DM: Cancer cell metabolism: Warburg and beyond. Cell 134: 703-707, 2008

45. Koppenol WH, Bounds PL and Dang CV: Otto Warburg's contributions to current concepts of cancer metabolism. Nat Rev Cancer 11: 325-337, 2011.

46. Chen G, Liu H, Zhang Y, Liang J, Zhu Y, Zhang M, Yu D, Wang $\mathrm{C}$ and Hou J: Silencing PFKP inhibits starvation-induced autophagy, glycolysis, and epithelial mesenchymal transition in oral squamous cell carcinoma. Exp Cell Res 370: 46-57, 2018.

47. Chen MK, Chiou HL, Su SC, Chung TT, Tseng HC, Tsai HT and Yang SF: The association between hypoxia inducible factor-1alpha gene polymorphisms and increased susceptibility to oral cancer. Oral Oncol 45: e222-e226, 2009.

48. Peerlings J, Van De Voorde L, Mitea C, Larue R, Yaromina A, Sandeleanu S, Spiegelberg L, Dubois L, Lambin P and Mottaghy FM: Hypoxia and hypoxia response-associated molecular markers in esophageal cancer: A systematic review. Methods 130: 51-62, 2017.

49. Hu X, Lin J, Jiang M, He X, Wang K, Wang W, Hu C, Shen Z, He Z, Lin H, et al: HIF-1 $\alpha$ Promotes the Metastasis of Esophageal Squamous Cell Carcinoma by Targeting SP1. J Cancer 11: 229-240, 2020.

50. Hu H, Zhu W, Qin J, Chen M, Gong L, Li L, Liu X, Tao Y, Yin H, Zhou H, et al: Acetylation of PGK1 promotes liver cancer cell proliferation and tumorigenesis. Hepatology 65: 515-528, 2017.

51. Qian X, Li X and Lu Z: Protein kinase activity of the glycolytic enzyme PGK1 regulates autophagy to promote tumorigenesis. Autophagy 13: 1246-1247, 2017.

52. Jang CH, Lee IA, Ha YR, Lim J, Sung MK, Lee SJ and Kim JS: PGK1 induction by a hydrogen peroxide treatment is suppressed by antioxidants in human colon carcinoma cells. Biosci Biotechnol Biochem 72: 1799-1808, 2008.

53. Fu D, He C, Wei J, Zhang Z, Luo Y, Tan H and Ren C: PGK1 is a potential survival biomarker and invasion promoter by regulating the HIF-1 $\alpha$-mediated epithelial-mesenchymal transition process in breast cancer. Cell Physiol Biochem 51: 2434-2444, 2018.

54. Patel SS, Shah KA, Shah MJ, Kothari KC and Rawal RM: Cancer stem cells and stemness markers in oral squamous cell carcinomas. Asian Pac J Cancer Prev 15: 8549-8556, 2014.

55. Mohajertehran F, Sahebkar A, Zare R and Mohtasham N: The promise of stem cell markers in the diagnosis and therapy of epithelial dysplasia and oral squamous cell carcinoma. J Cell Physiol 233: 8499-8507, 2018.

56. Murugan AK, Munirajan AK and Tsuchida N: Ras oncogenes in oral cancer: The past 20 years. Oral Oncol 48: 383-392, 2012.

57. Lee MS, Jeong MH, Lee HW, Han HJ, Ko A, Hewitt SM, Kim JH, Chun KH, Chung JY, Lee C, et al: PI3K/AKT activation induces PTEN ubiquitination and destabilization accelerating tumourigenesis. Nat Commun 6: 7769, 2015.

58. Song Y, Zheng S, Wang J, Long H, Fang L, Wang G, Li Z, Que T, Liu Y, Li Y, et al: Hypoxia-induced PLOD2 promotes proliferation, migration and invasion via $\mathrm{PI} 3 \mathrm{~K} / \mathrm{Akt}$ signaling in glioma. Oncotarget 8: 41947-41962, 2017.

59. Yu J, Luo Y and Wen Q: Nalbuphine suppresses breast cancer stem-like properties and epithelial-mesenchymal transition via the AKT-NFкB signaling pathway. J Exp Clin Cancer Res 38: 197, 2019.

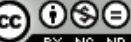

This work is licensed under a Creative Commons Attribution-NonCommercial-NoDerivatives 4.0 International (CC BY-NC-ND 4.0) License. 